\title{
Gold(I)-Catalyzed Intramolecular Enantioselective Hydroarylation of Allenes with Indoles
}

Cong Liu and Ross A. Widenhoefer*

French Family Science Center

Duke University

Durham, NC 27708-0346

Experimental procedures, mechanistic schemes for the cyclization of $\mathbf{1 0}$ and 11, and scans of chiral HPLC traces and NMR spectra for tricyclic indoles (25 pages). 


\subsection{Experimental Section}

General Methods. Catalytic reactions were performed in sealed glass tubes under an atmosphere of dry nitrogen unless noted otherwise. NMR spectra were obtained on a Varian spectrometer operating at $400 \mathrm{MHz}$ for ${ }^{1} \mathrm{H}$ NMR and $100 \mathrm{MHz}$ for ${ }^{13} \mathrm{C} \mathrm{NMR} \mathrm{in} \mathrm{CDCl}_{3}$ at room temperature. Gas chromatography was performed on a Hewlett-Packard 5890 gas chromatograph equipped with a 25 m polydimethylsiloxane capillary column. Chiral HPLC was performed on a Hewlett-Packard chromatograph equipped with a $25 \mathrm{~cm}$ Chiralpak AD-H column detecting absorbance at $245 \mathrm{~nm}$. Flash column chromatography was performed employing 200-400 mesh silica gel (EM). THF was distilled from sodium/benzophenone ketyl. All other solvents were purchased in anhydrous form and were used as received. Silver salts (Strem) were used as received and stored in an inert atmosphere glove box prior to use. Bis(gold) complexes were synthesized employing the method of Echavarren. ${ }^{1}$ 2-Allenyl indoles were synthesized according to published procedures. $^{2}$ All tricyclic indoles have been previously reported; ${ }^{2}$ NMR spectra of the purified products of hydroarylation are included in Figures S9-S24.

\section{Enantioselective Hydroarylation of 4 catalyzed by $[(S)-2] \mathrm{Au}_{2} \mathrm{Cl}_{2} / \mathrm{AgBF}_{4}$.}

A mixture of $[(S)-2] \mathrm{Au}_{2} \mathrm{Cl}_{2}\left(5.1 \mathrm{mg}, 3.1 \times 10^{-3} \mathrm{mmol}\right)$ and $\mathrm{AgBF}_{4}\left(1.2 \mathrm{mg}, 6.3 \times 10^{-3}\right.$ $\mathrm{mmol})$ in toluene $(0.2 \mathrm{~mL})$ was stirred at $-20^{\circ} \mathrm{C}$ for $10 \mathrm{~min}$. To this, a solution of $4(41 \mathrm{mg}$, $0.13 \mathrm{mmol})$ in toluene $(0.3 \mathrm{~mL})$ was added via syringe. The resulting mixture was maintained at $-10{ }^{\circ} \mathrm{C}$ for $17 \mathrm{~h}$. Column chromatography of the reaction mixture 
(hexanes-EtOAc $=10: 1 \rightarrow 5: 1)$ gave $5(71 \mathrm{mg}, 87 \%)$ as a pale yellow oil. The enantiomeric excess of $\mathbf{5}$ was determined by chiral HPLC analysis (Figure S1).

The remaining enantiomerically enriched tricyclic indoles were synthesized employing a procedure similar to that used to synthesize 5. The enantiomeric excess of each of these tricyclic indoles was determined by HPLC analysis (Figures S2-S8).

Scheme 1. Potential pathways for the intramolecular hydroarylation of $\mathbf{1 0}$ catalyzed by $[(S)-2] \mathrm{Au}_{2} \mathrm{Cl}_{2} / \mathrm{AgBF}_{4}$

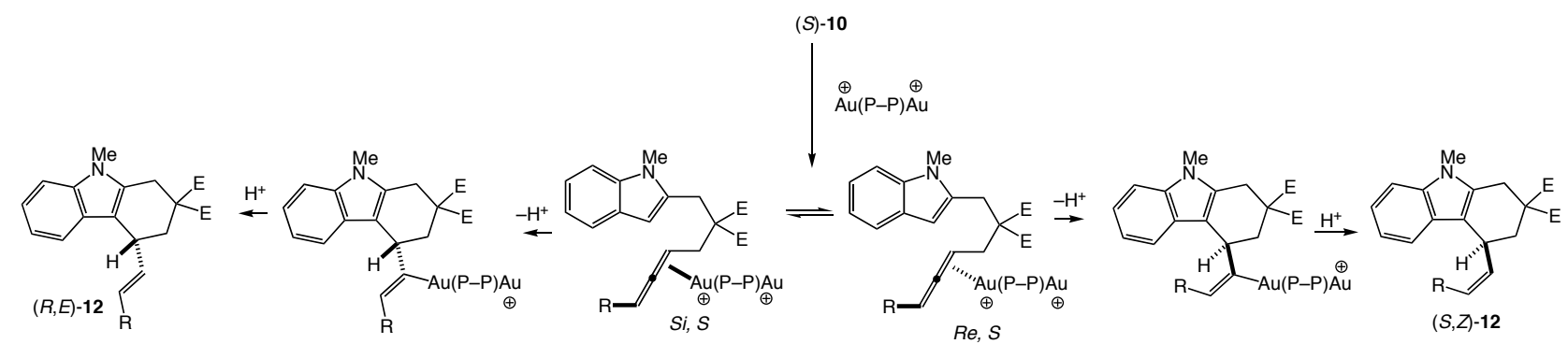

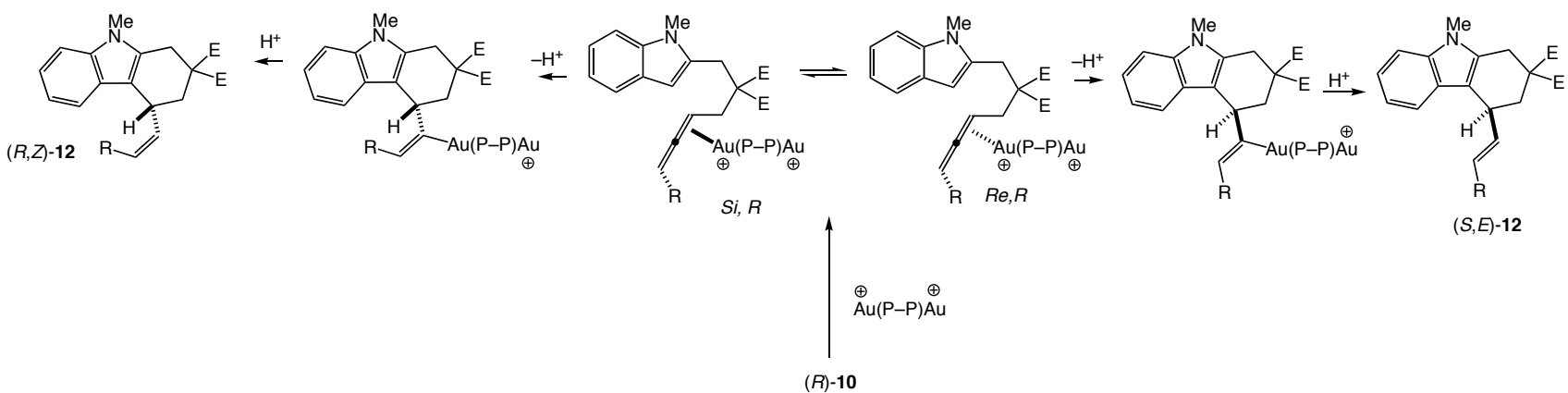


Scheme 2. Potential pathways for the intramolecular hydroarylation of 11 catalyzed by $[(S)-2] \mathrm{Au}_{2} \mathrm{Cl}_{2} / \mathrm{AgBF}_{4}$
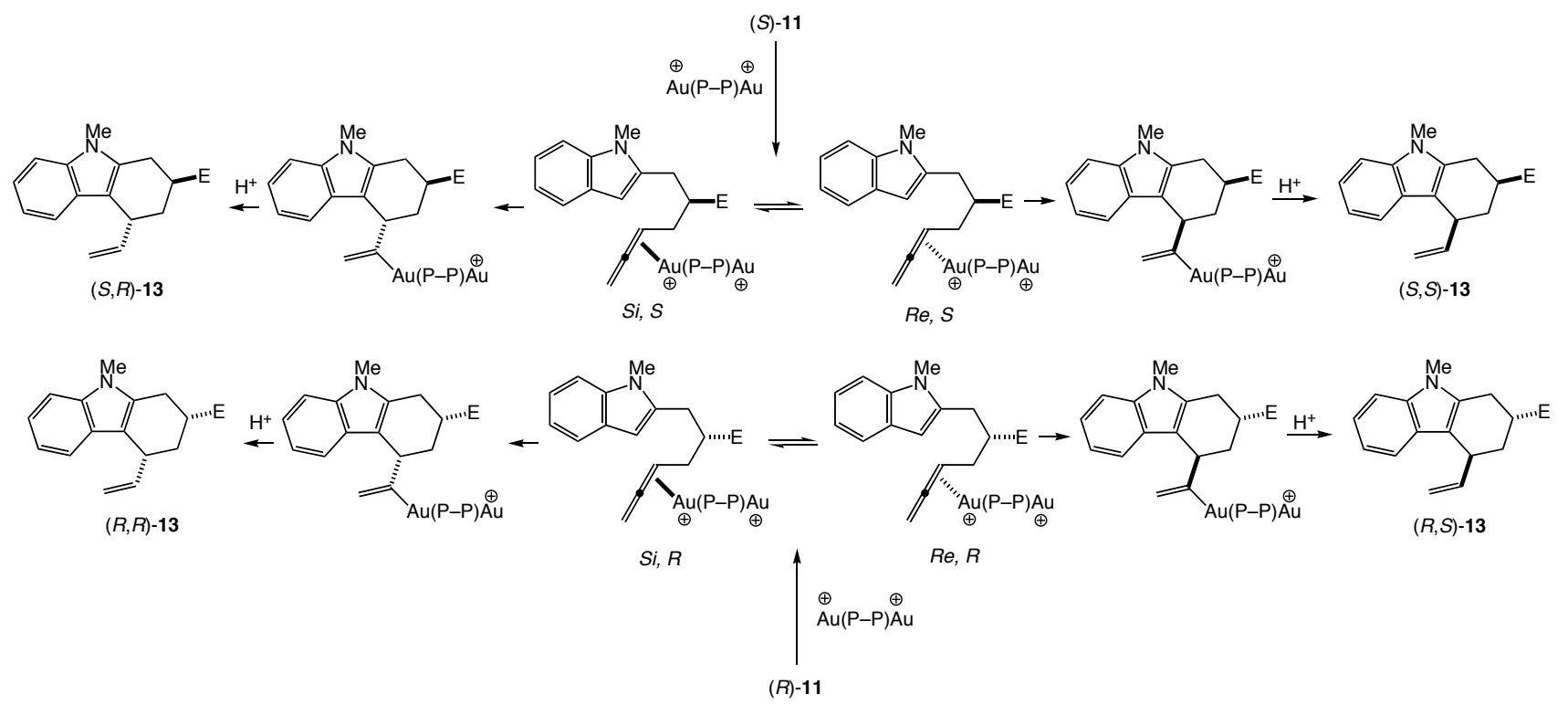

Figure S1. HPLC trace for racemic (left trace) and enantiomerically enriched (92\% ee, right trace) 5. The enantiomers eluted at 35.32 and $37.06 \mathrm{~min}$ (hexanes-isopropanol = 97:3@0.3 mL/min).
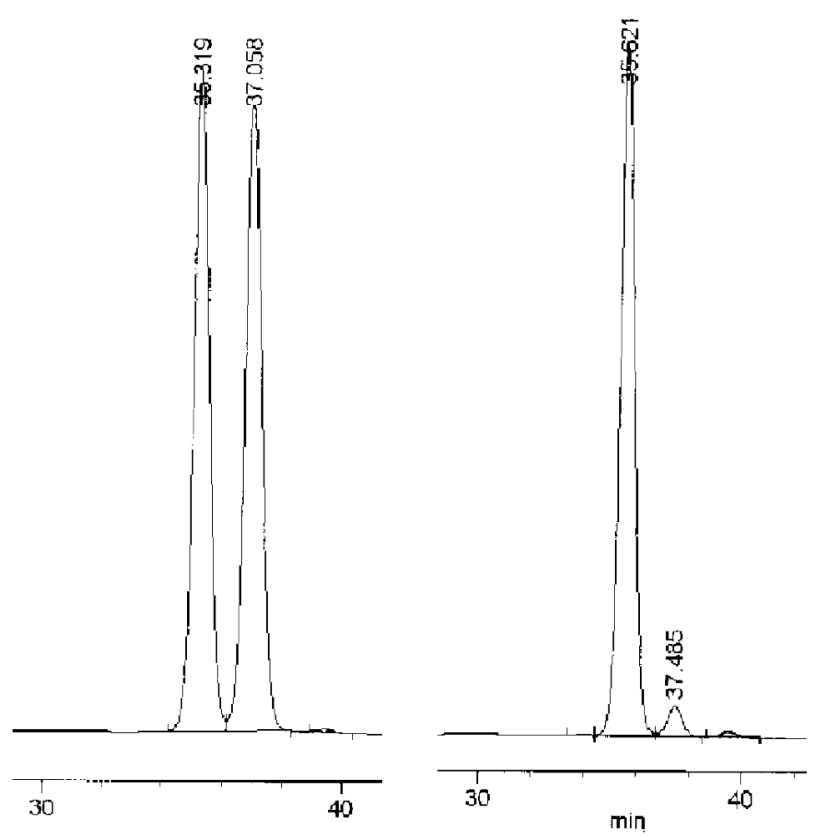
Figure S2. HPLC trace for racemic (left trace) and enantiomerically enriched (right trace) 6-methoxy-2,2-dimethoxycarbonyl-9-methyl-4-vinyl-2,3,4,9-tetrahydrocarbazole (Table 2, entry 2). The enantiomers eluted at 16.39 and $20.52 \mathrm{~min}$ (hexanes-isopropanol = 90:10 @ $0.5 \mathrm{~mL} / \mathrm{min})$.
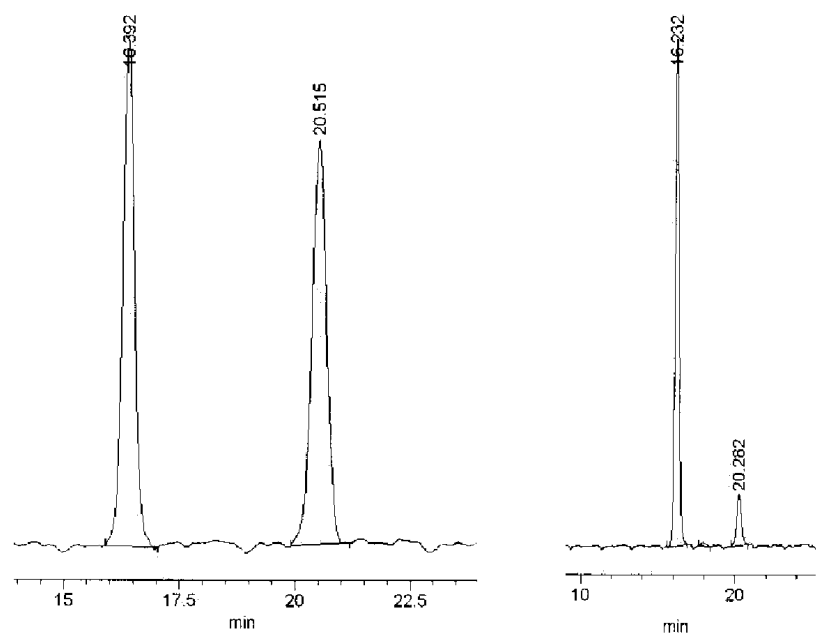

Figure S3. HPLC trace for racemic (left trace) and enantiomerically enriched (right trace) 6-fluoro-2,2-dimethoxycarbonyl-9-methyl-4-vinyl-2,3,4,9-tetrahydrocarbazole (Table 2, entry 3). The enantiomers eluted at 13.24 and $14.13 \mathrm{~min}$ (hexanes-isopropanol = 90:10 @ 0.5 $\mathrm{mL} / \mathrm{min})$.
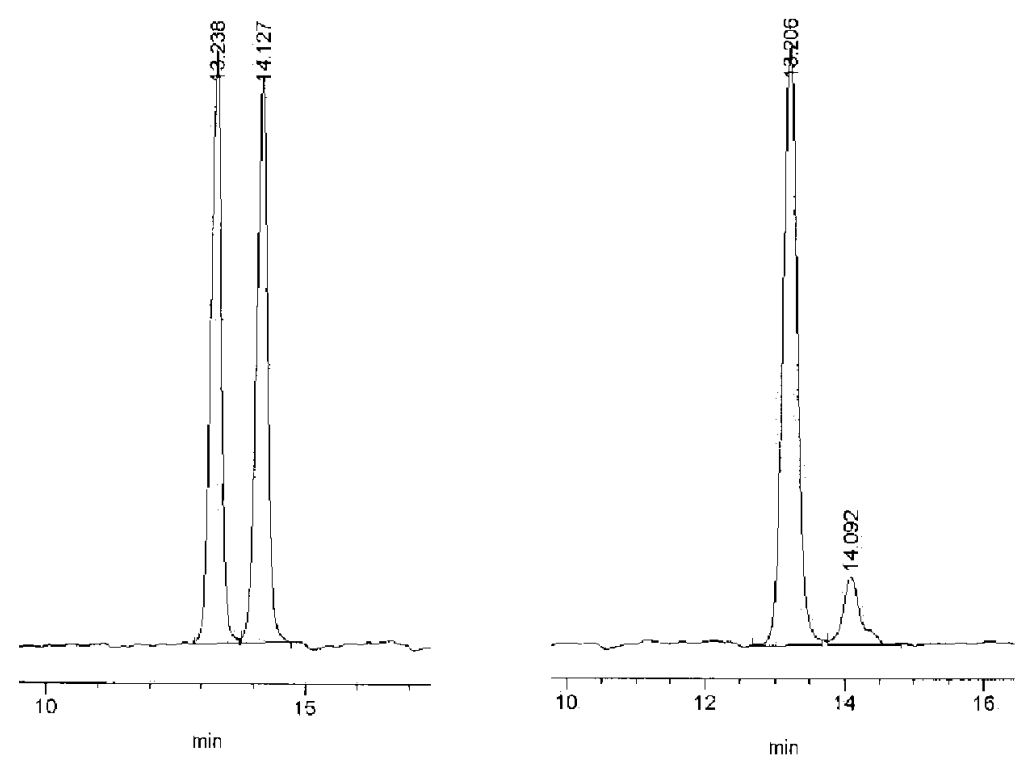
Figure S4. HPLC trace for racemic (left trace) and enantiomerically enriched (right trace) 2,2-bis(hydroxymethyl)-9-methyl-4-vinyl-2,3,4,9-tetrahydrocarbazole (Table 2, entry 4). The enantiomers eluted at 21.01 and $31.44 \mathrm{~min}$ (hexanes-isopropanol = 90:10 @ 0.5 $\mathrm{mL} / \mathrm{min}$ ). The peak indicated with " $\mathrm{x}$ " corresponds to an impurity.
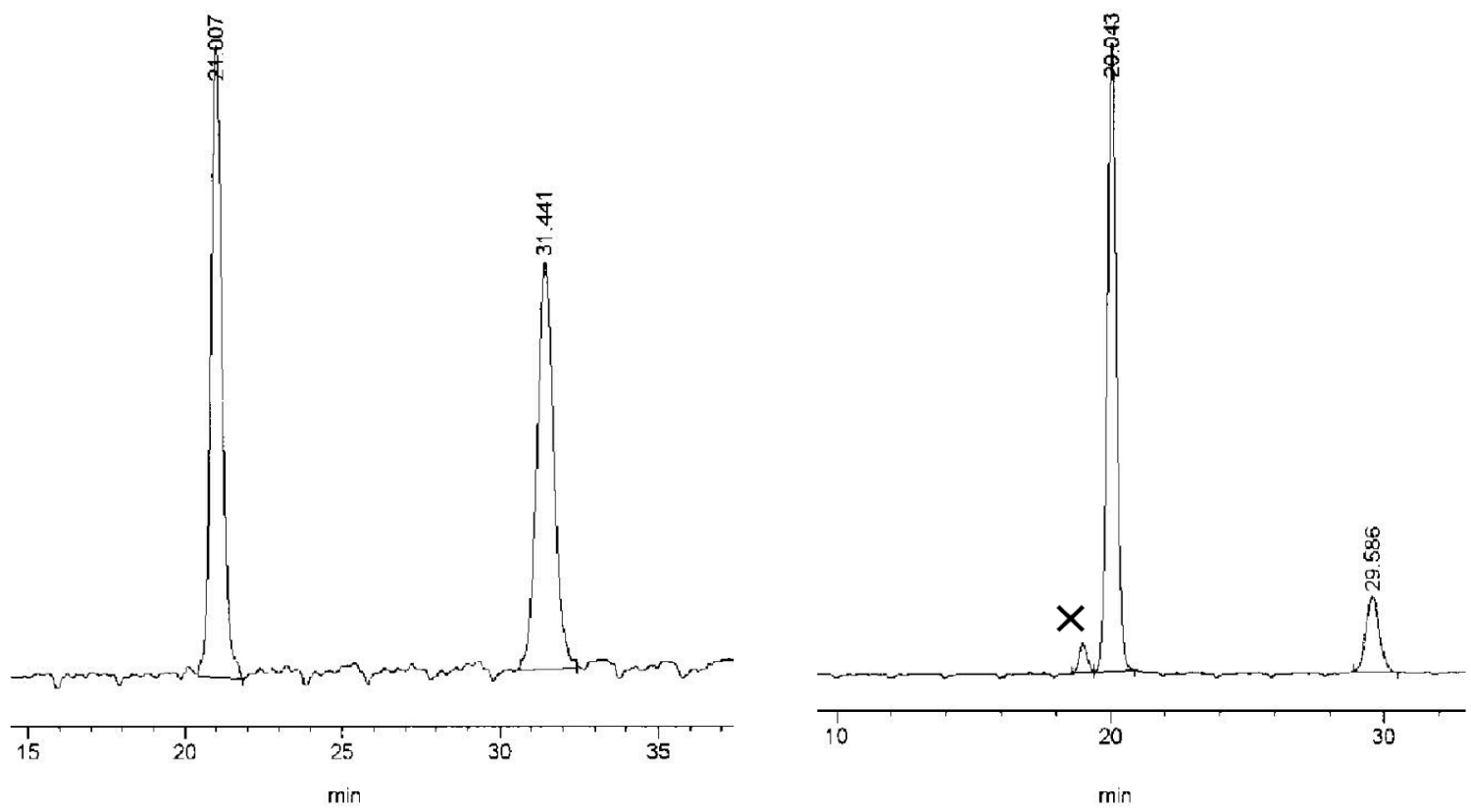

Figure S5. HPLC trace for racemic (left trace) and enantiomerically enriched (right trace) 7. The enantiomers eluted at 41.53 and 44.18 min (hexanes-isopropanol = 99:1 @ 0.3 $\mathrm{mL} / \mathrm{min})$.
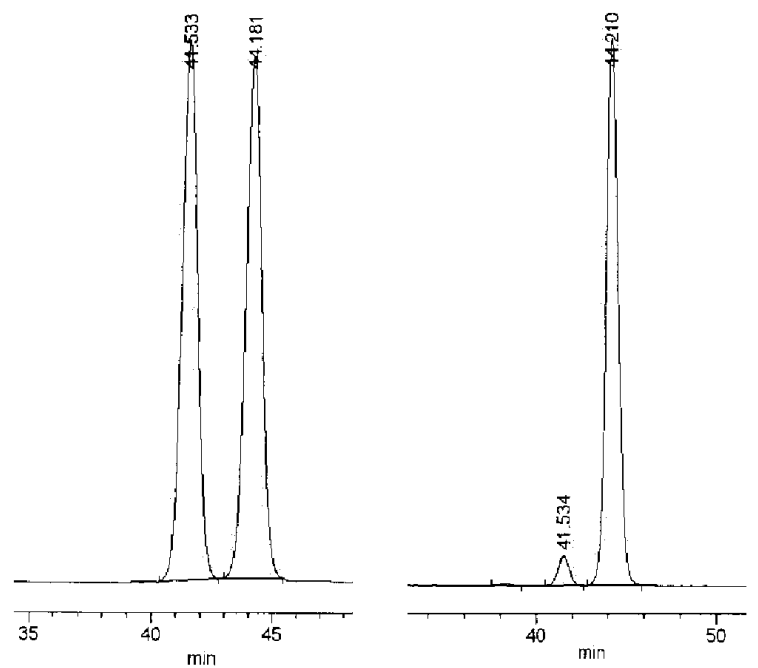
Figure S6. HPLC trace for racemic (left trace) and enantiomerically enriched (right trace) 9. The enantiomers eluted at 42.76 and 44.98 min (hexanes-isopropanol = 97:3 @ 0.3 $\mathrm{mL} / \mathrm{min})$.
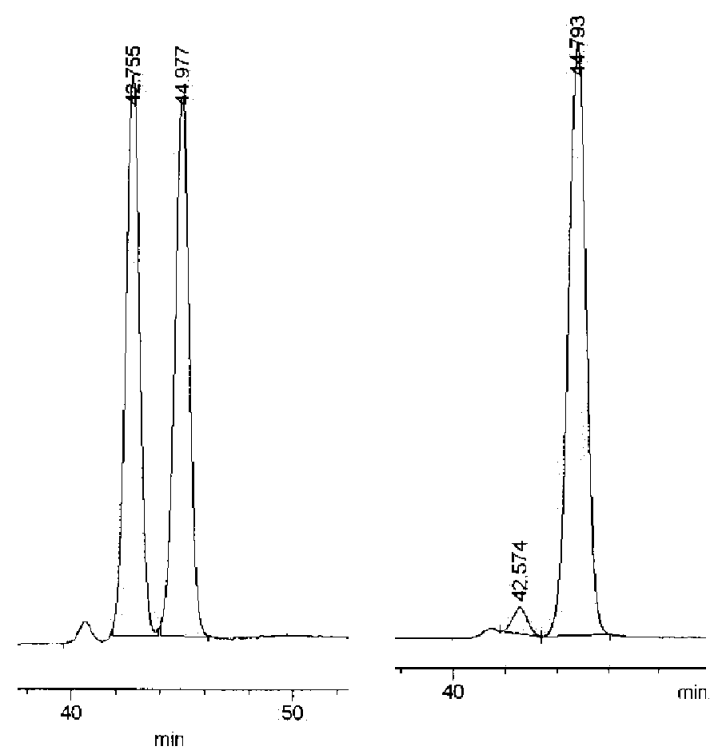

Figure S7. HPLC trace for racemic, diastereomerically pure $(E)-12$ (left trace) and a 28:1 enantiomerically enriched mixture of $(E)-12$ and $(Z)-12$ (right trace) The enantiomers of $(E)-12$ and (Z)-12 eluted at 23.34 and $27.05 \mathrm{~min}$ and 22.43 and $25.33 \mathrm{~min}$, respectively (hexanes-isopropanol=97:3@0.3 mL/min).
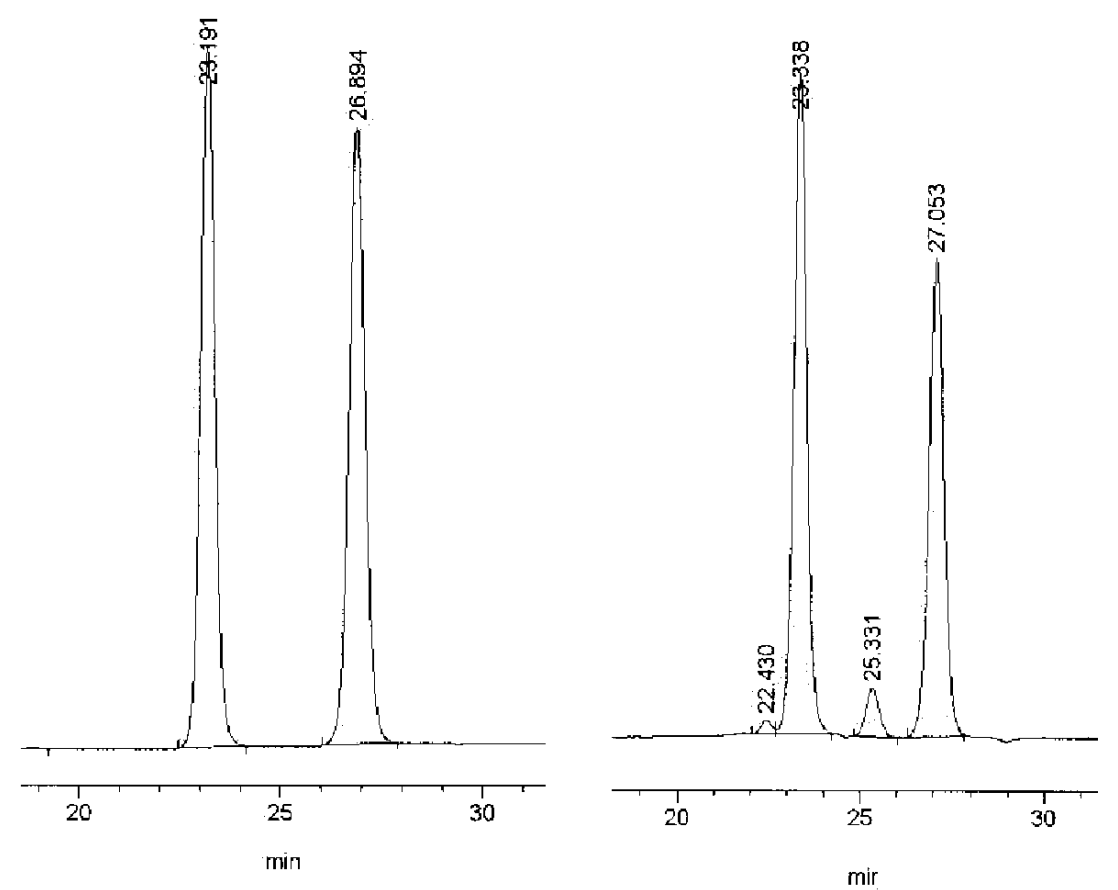
Figure S8. HPLC trace of a racemic 5:1 mixture of cis-13 and trans-13 (left trace) and an enantiomerically enriched 9:1 mixture of cis-13 and trans-13 (right trace). The enantiomers of cis-13 and trans-13 eluted at 43.28 and $49.20 \mathrm{~min}$ and 39.85 and $43.28 \mathrm{~min}$, respectively (hexanes-isopropanol=99:1 @ $0.3 \mathrm{~mL} / \mathrm{min}$ ).
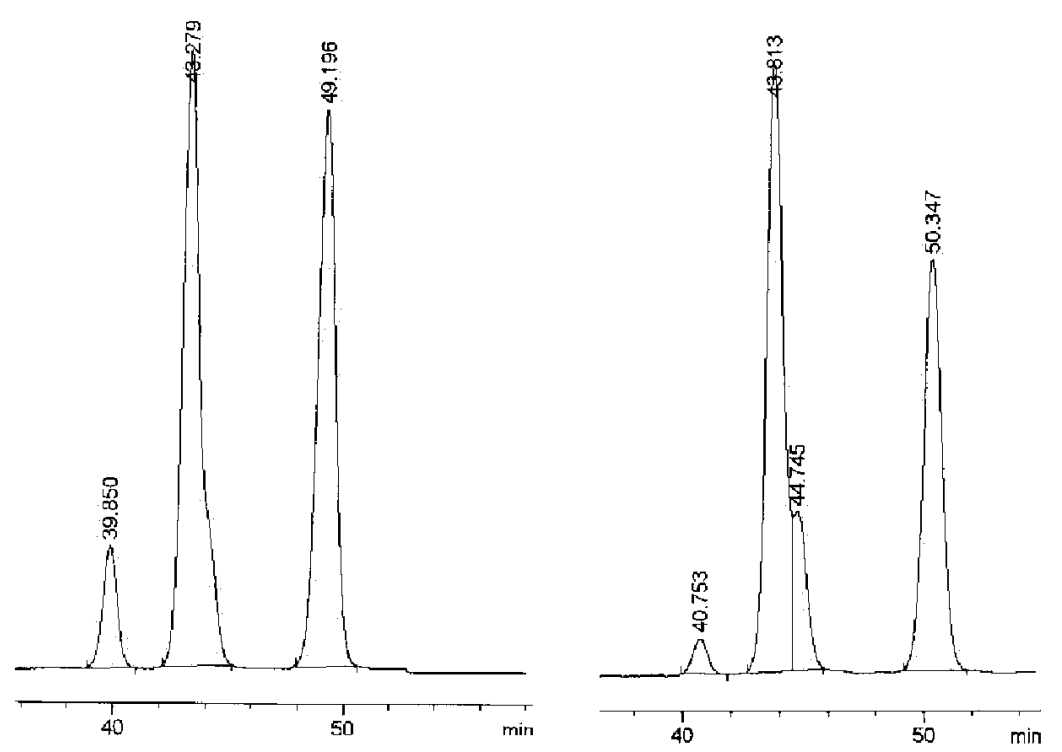
Figure S9. ${ }^{1} \mathrm{H}$ NMR spectrum of 5 .

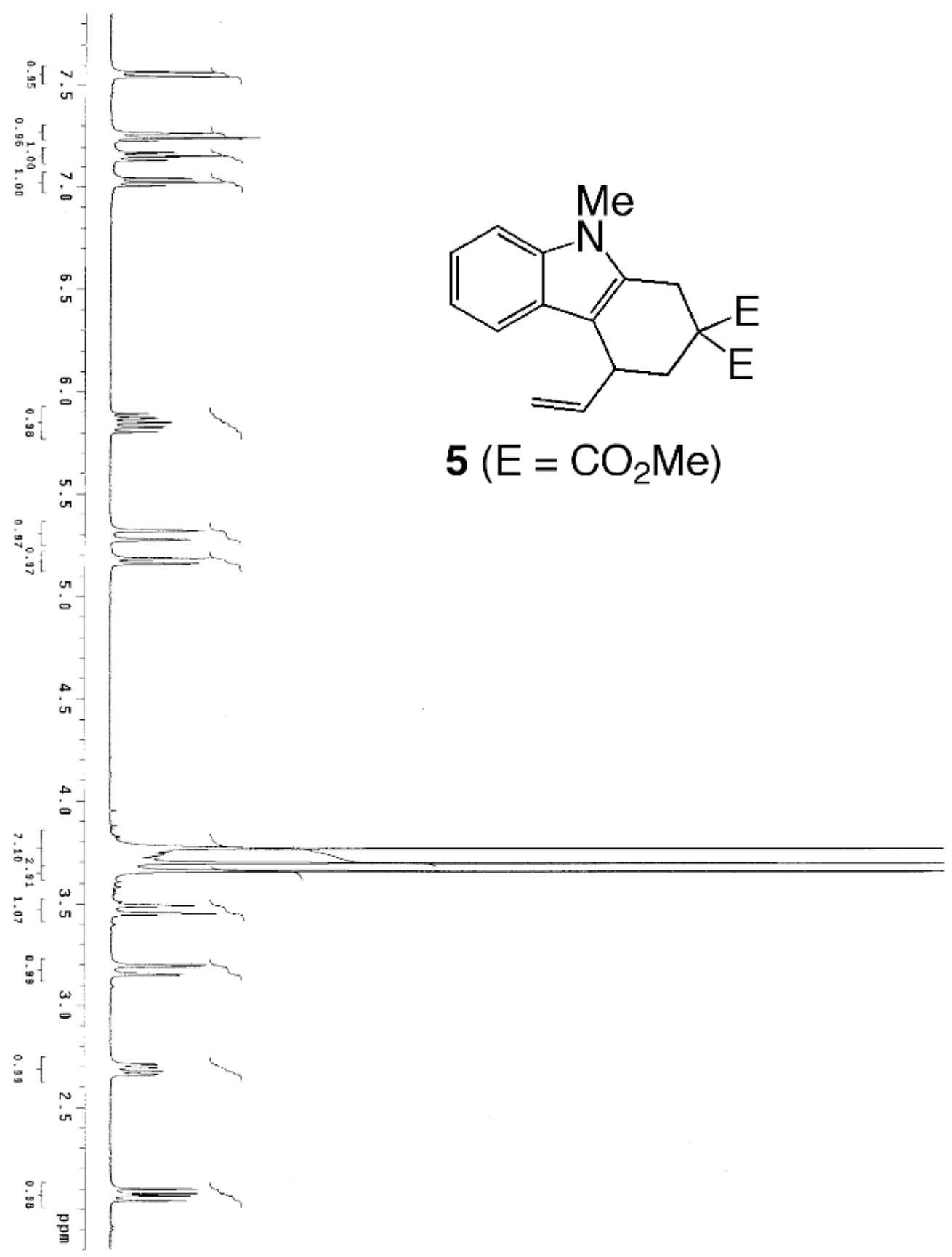


Figure S10. ${ }^{13} \mathrm{C}\left\{{ }^{1} \mathrm{H}\right\}$ NMR spectrum of 5 .

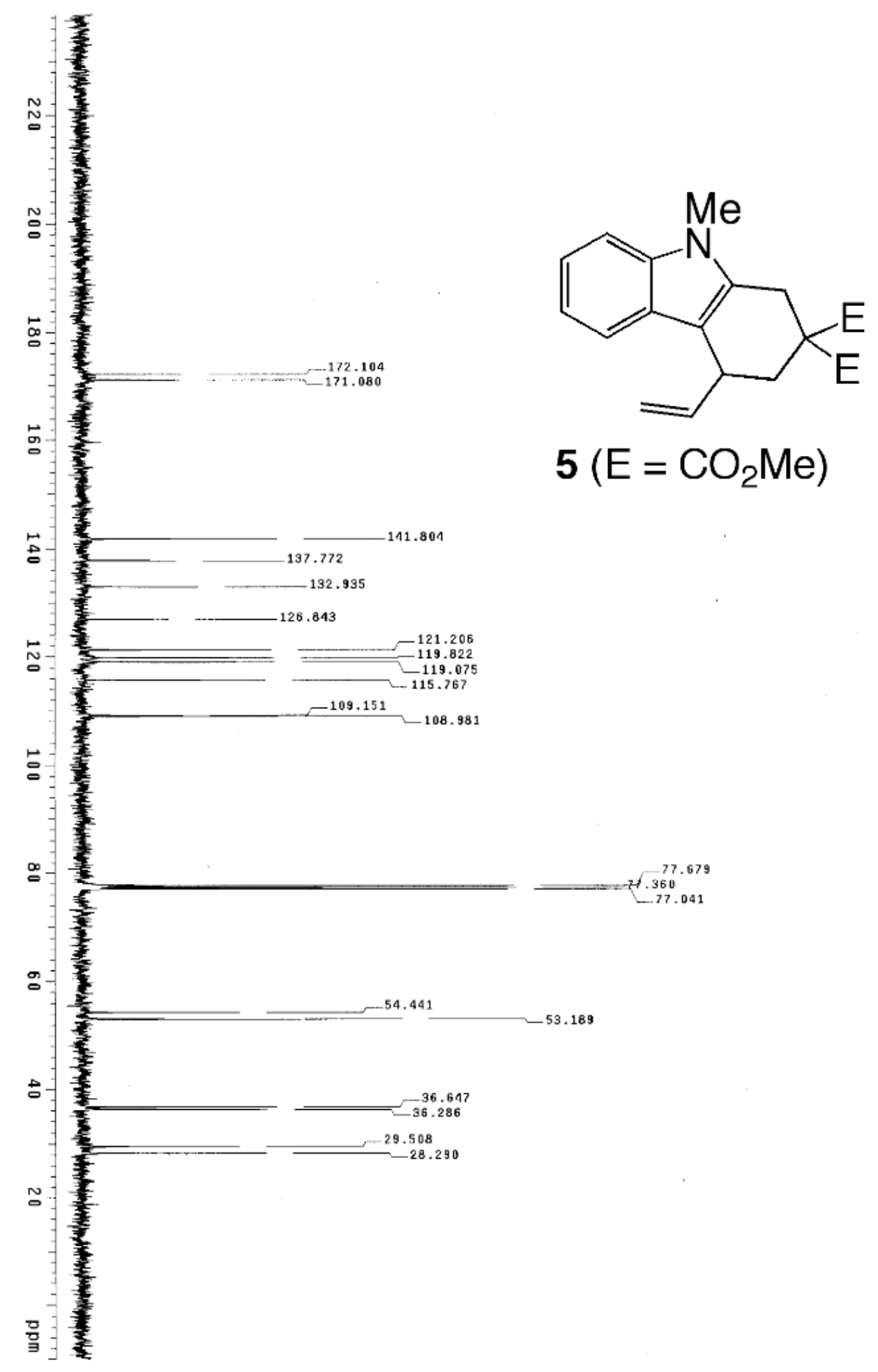


Figure S11. ${ }^{1} \mathrm{H}$ NMR spectrum of

6-methoxy-2,2-dimethoxycarbonyl-9-methyl-4-vinyl-2,3,4,9-tetrahydrocarbazole.

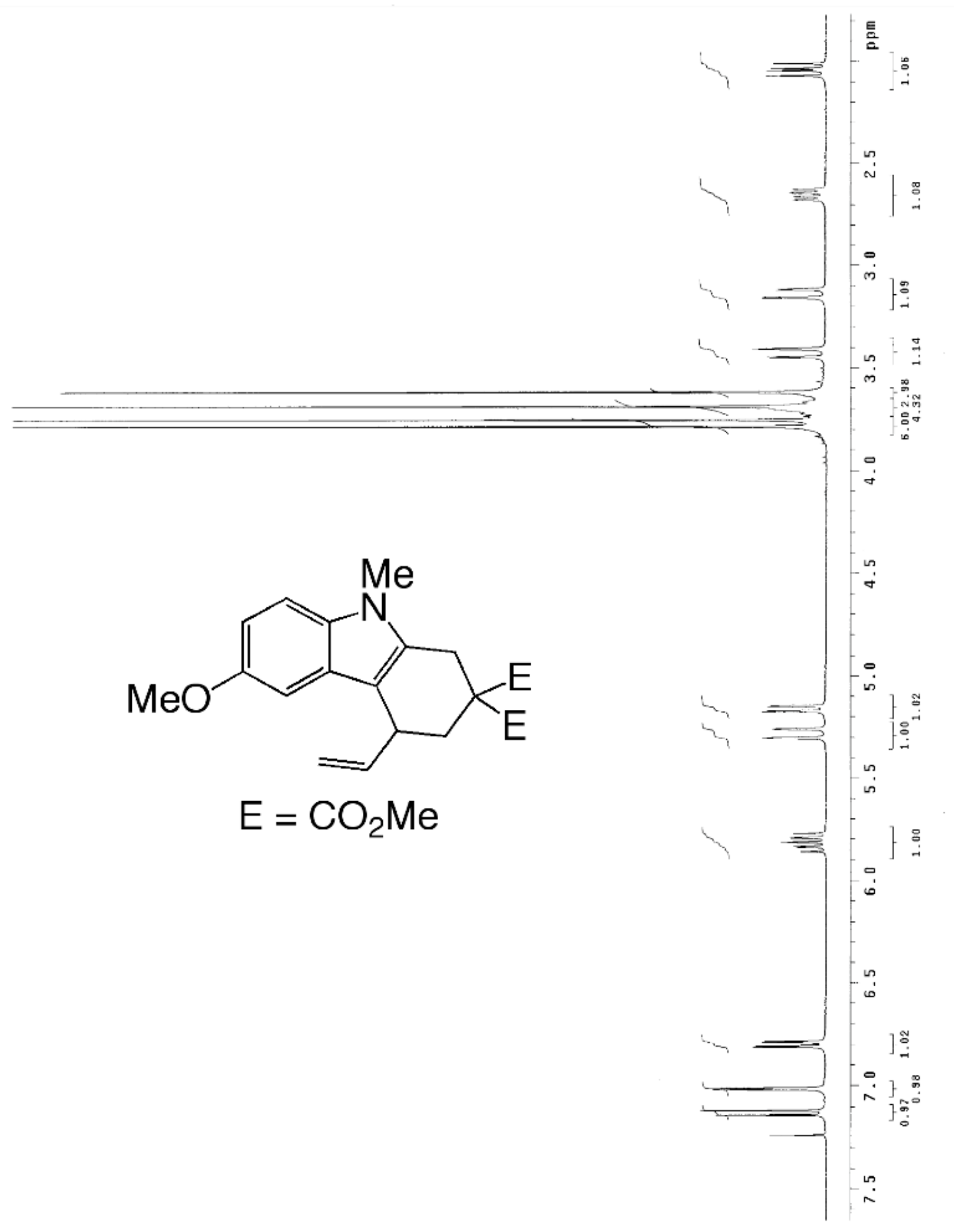


Figure S12. ${ }^{13} \mathrm{C}\left\{{ }^{1} \mathrm{H}\right\}$ NMR spectrum of

6-methoxy-2,2-dimethoxycarbonyl-9-methyl-4-vinyl-2,3,4,9-tetrahydrocarbazole.

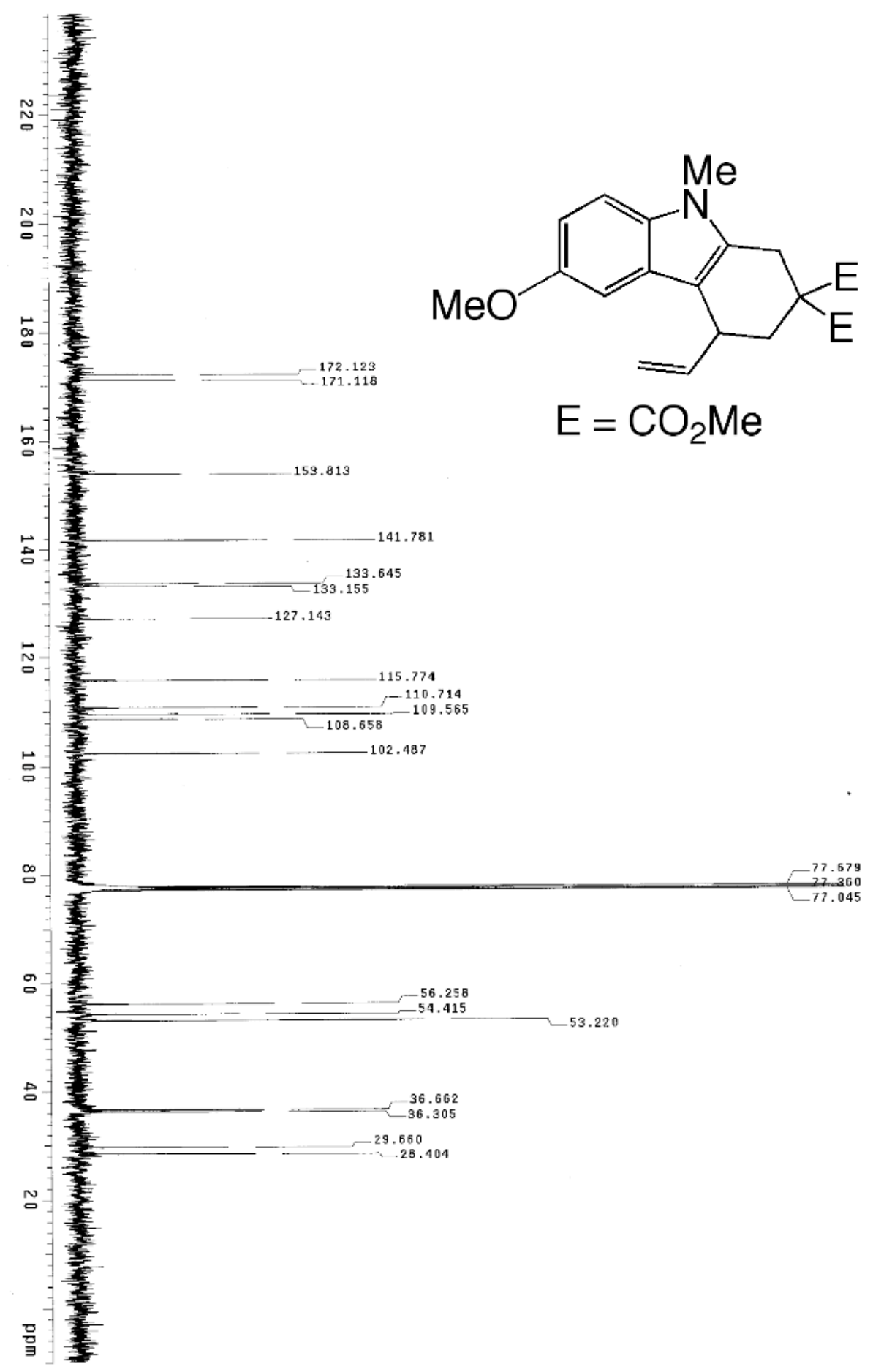


Figure S13. ${ }^{1} \mathrm{H}$ NMR spectrum of

6-fluoro-2,2-dimethoxycarbonyl-9-methyl-4-vinyl-2,3,4,9-tetrahydrocarbazole.

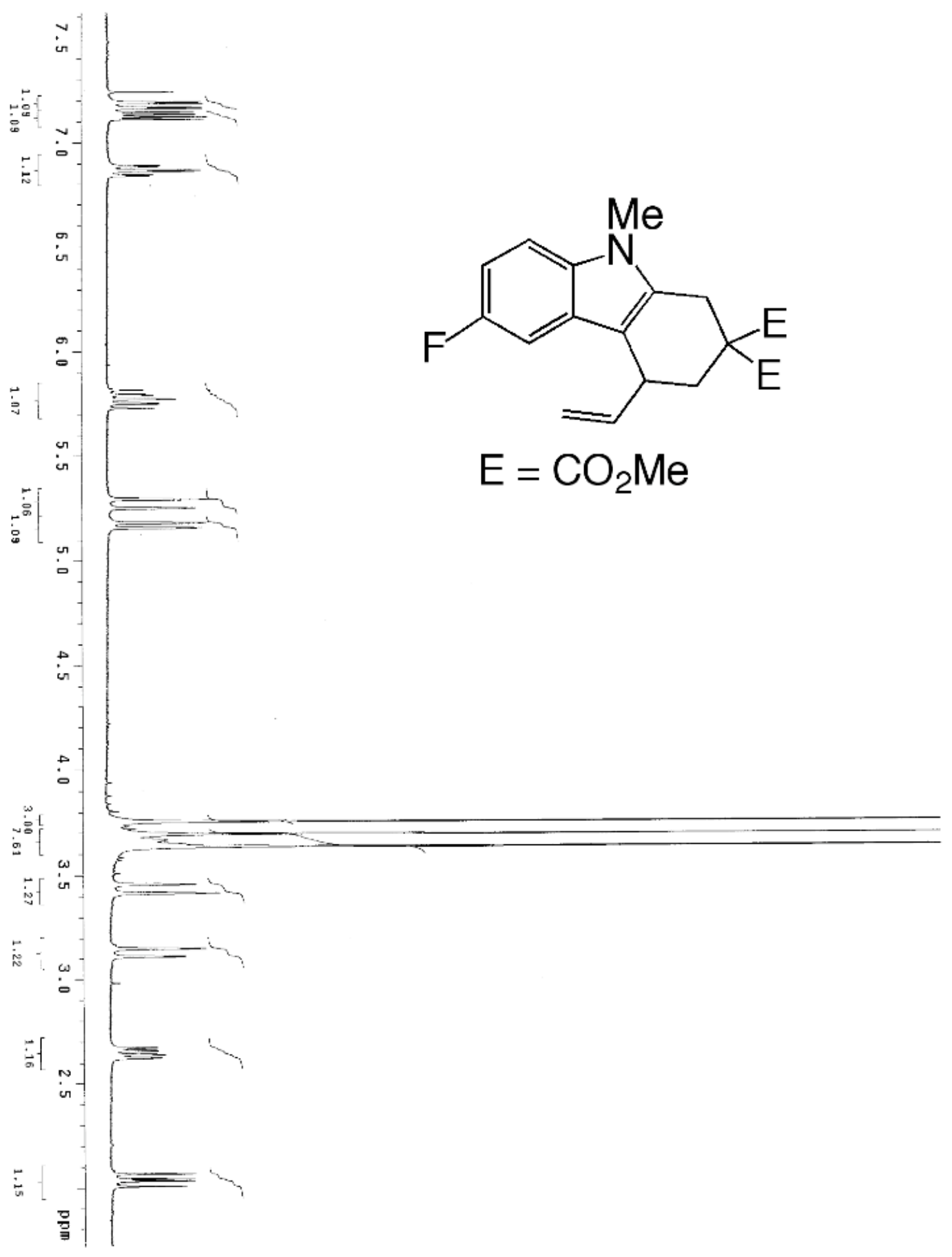


Figure S14. ${ }^{13} \mathrm{C}\left\{{ }^{1} \mathrm{H}\right\}$ NMR spectrum of

6-fluoro-2,2-dimethoxycarbonyl-9-methyl-4-vinyl-2,3,4,9-tetrahydrocarbazole.

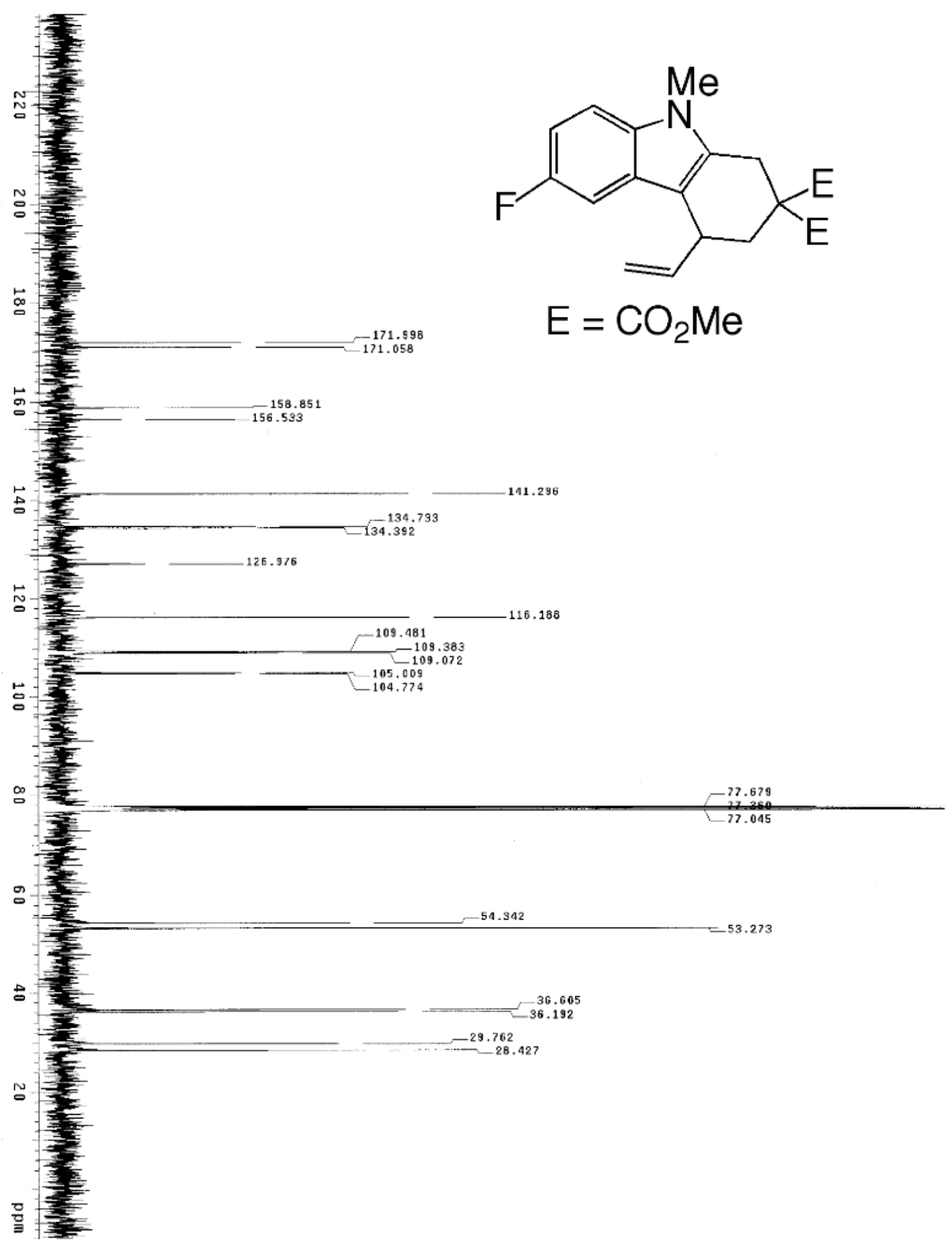


Figure S15. $\quad{ }^{1} \mathrm{H}$ NMR spectrum of

2,2-bis(hydroxymethyl)-9-methyl-4-vinyl-2,3,4,9-tetrahydrocarbazole.

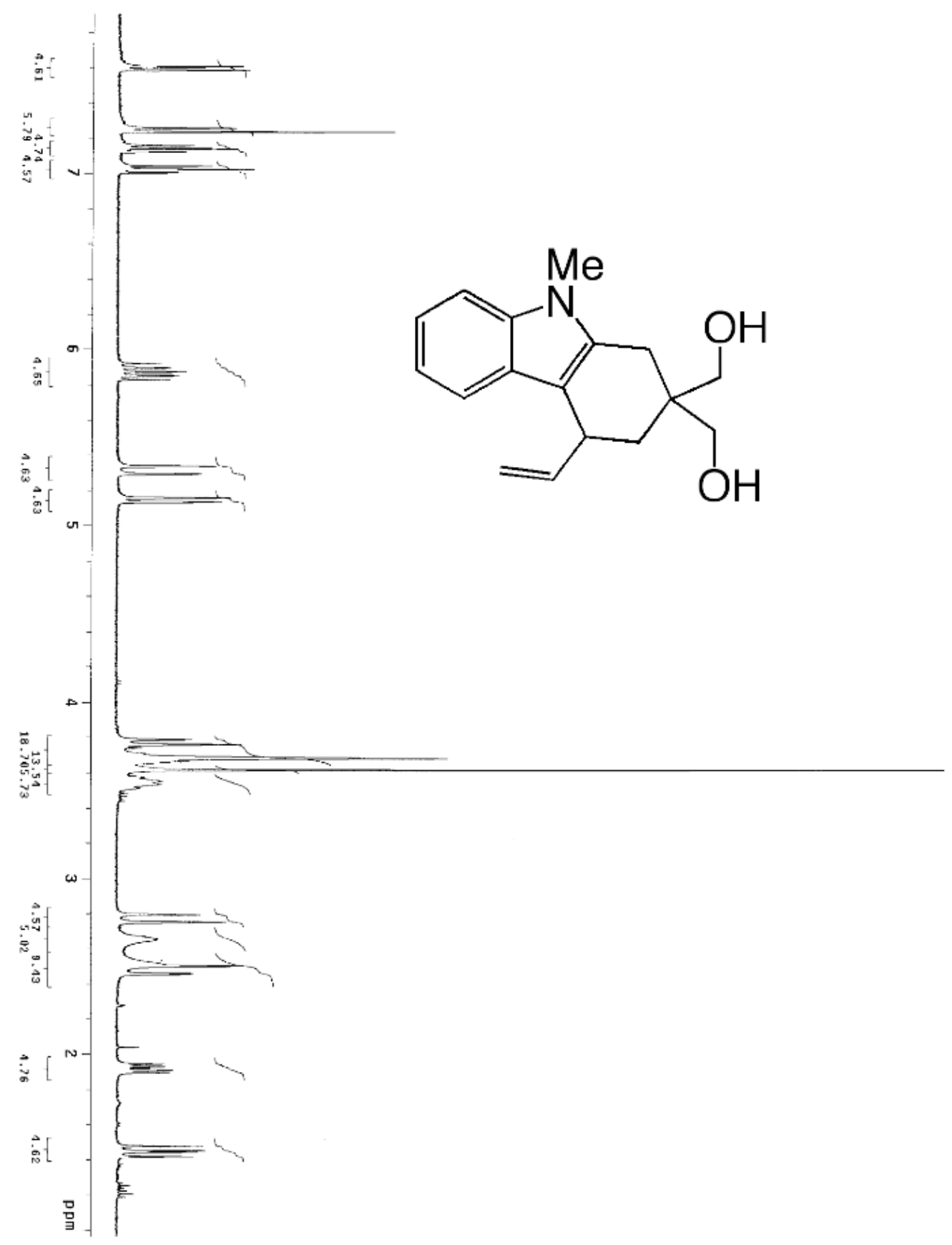


Figure S16. ${ }^{13} \mathrm{C}\left\{{ }^{1} \mathrm{H}\right\}$ NMR spectrum of

2,2-bis(hydroxymethyl)-9-methyl-4-vinyl-2,3,4,9-tetrahydrocarbazole.

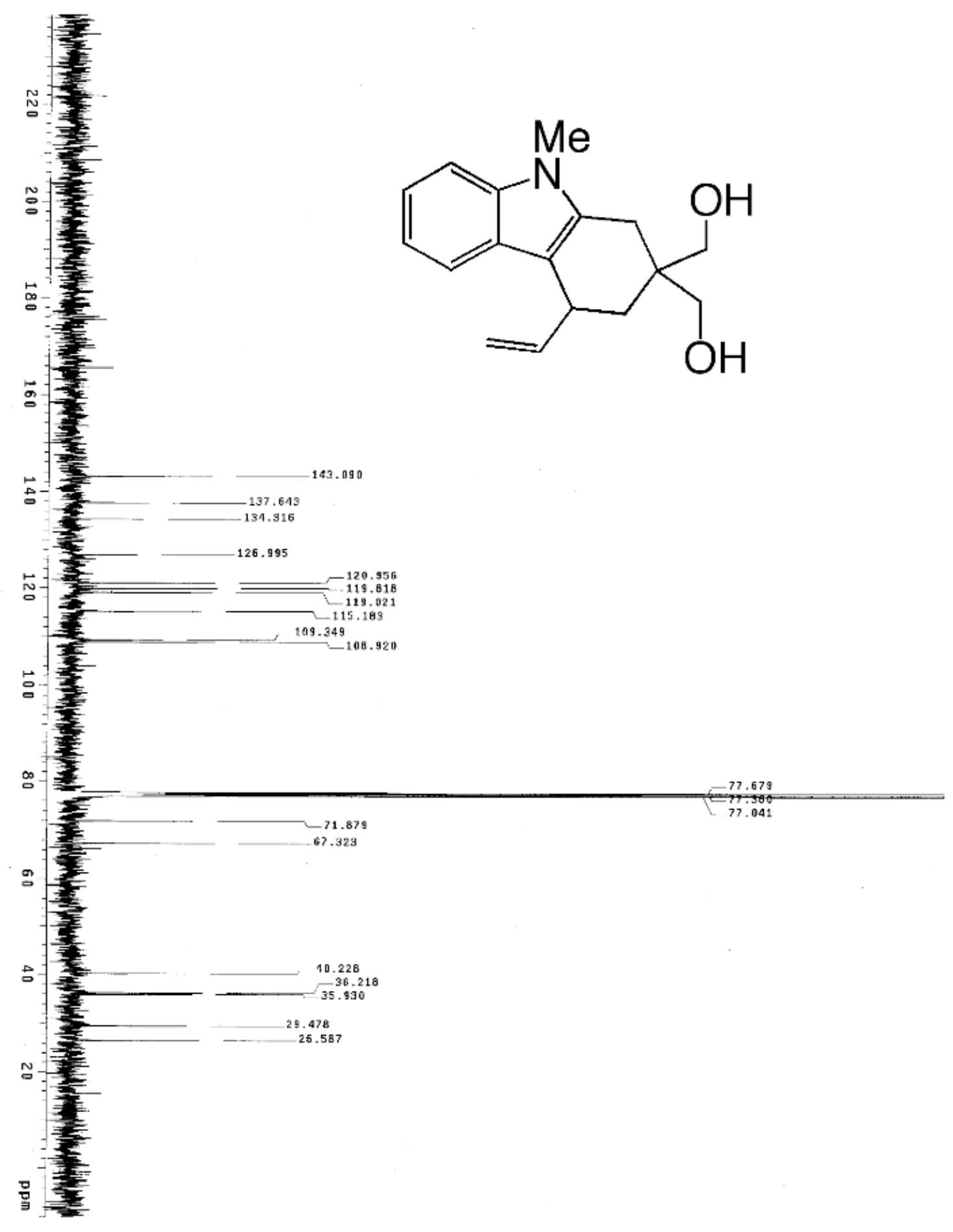


Figure S17. ${ }^{1} \mathrm{H}$ NMR spectrum of 7.

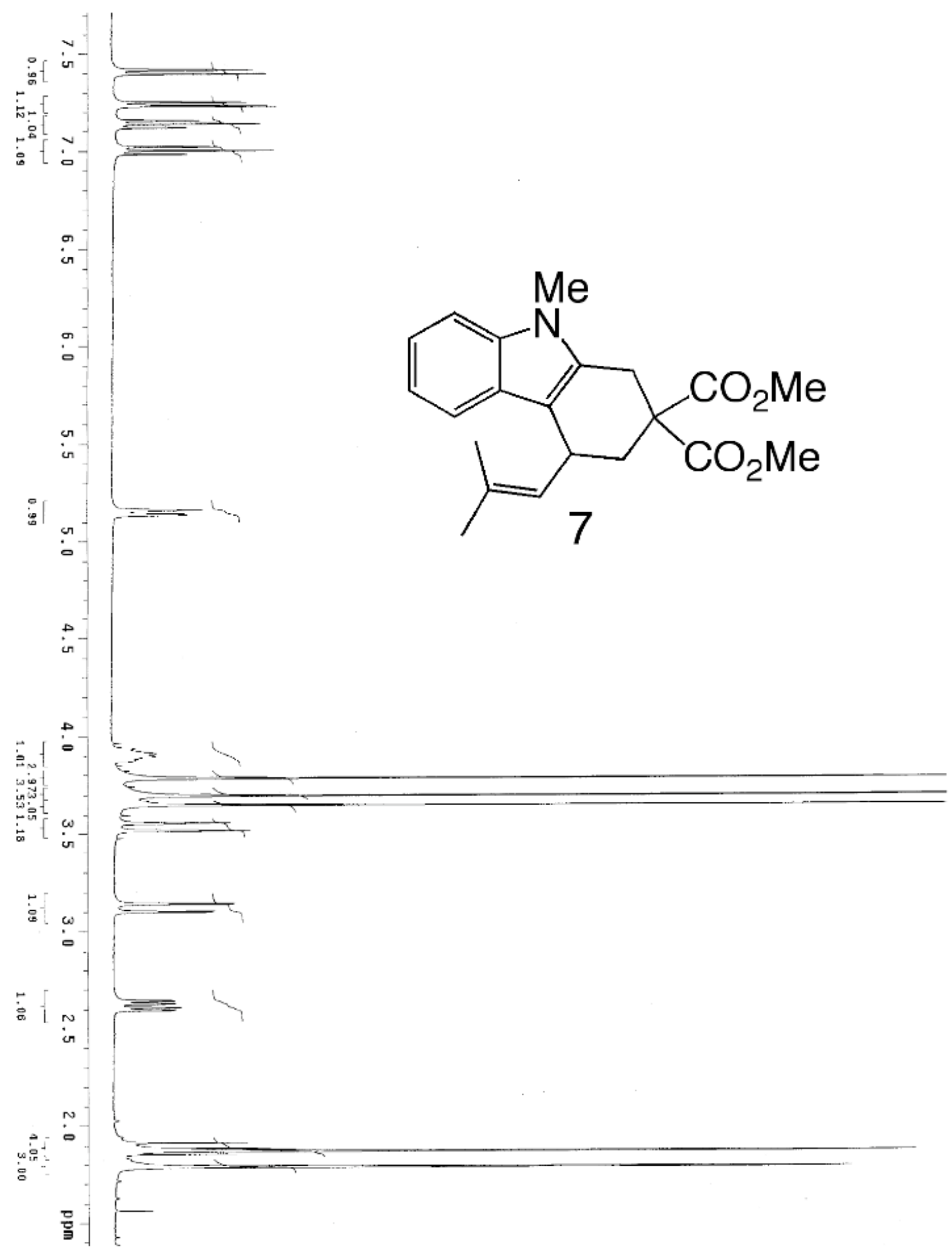


Figure S18. ${ }^{13} \mathrm{C}\left\{{ }^{1} \mathrm{H}\right\}$ NMR spectrum of 7.

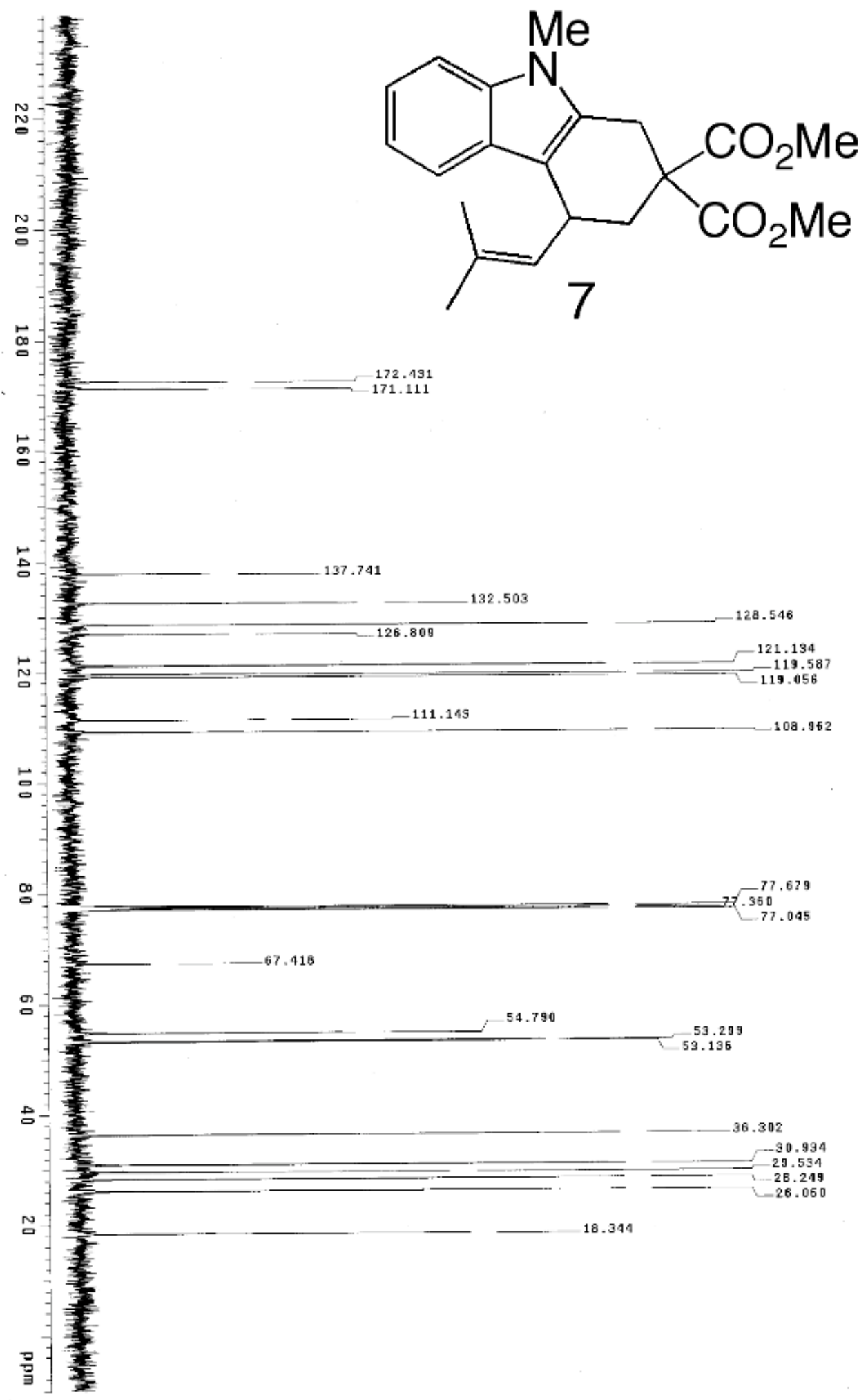


Figure S19. ${ }^{1} \mathrm{H}$ NMR spectrum of 9.

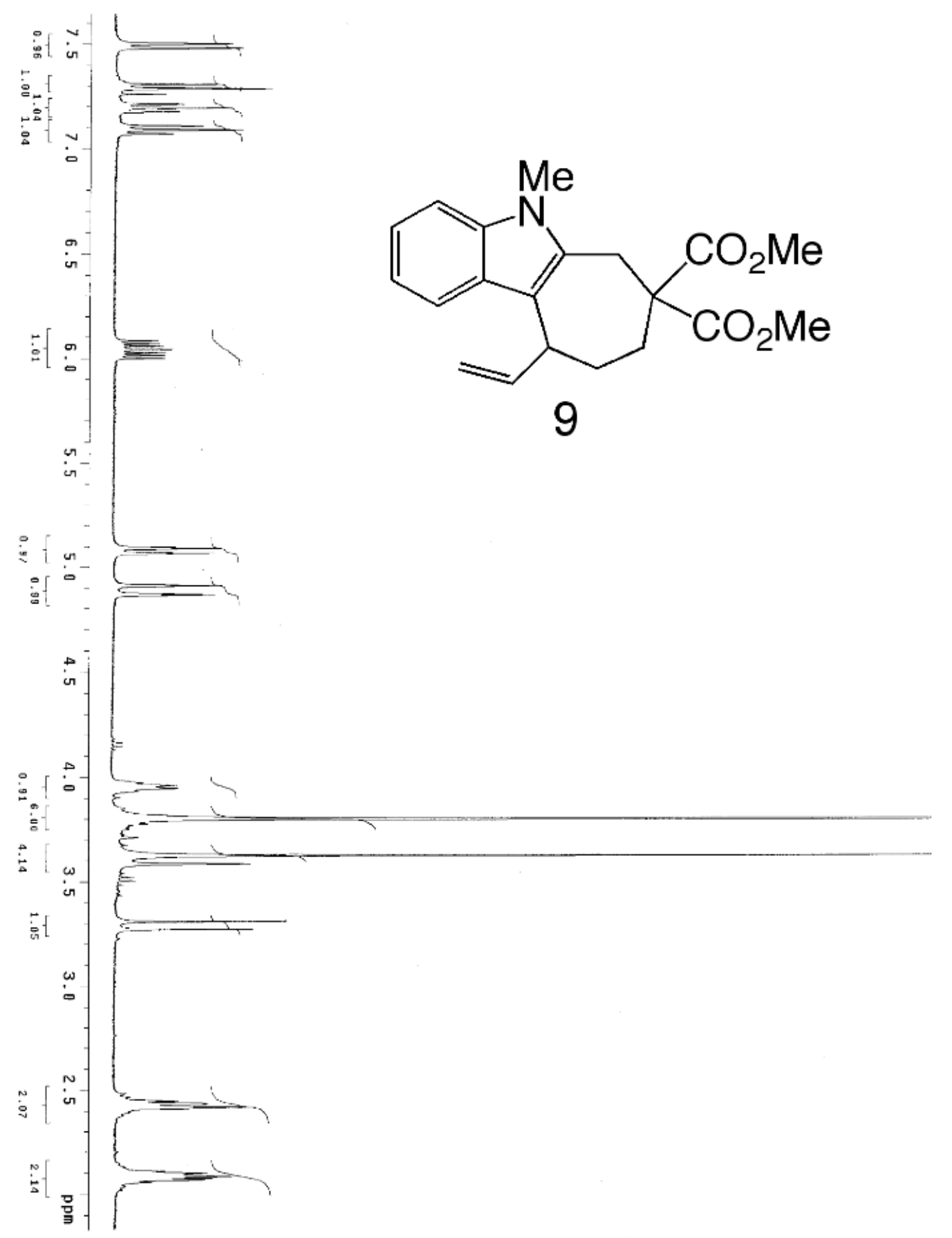


Figure S20. ${ }^{13} \mathrm{C}\left\{{ }^{1} \mathrm{H}\right\}$ NMR spectrum of 9.

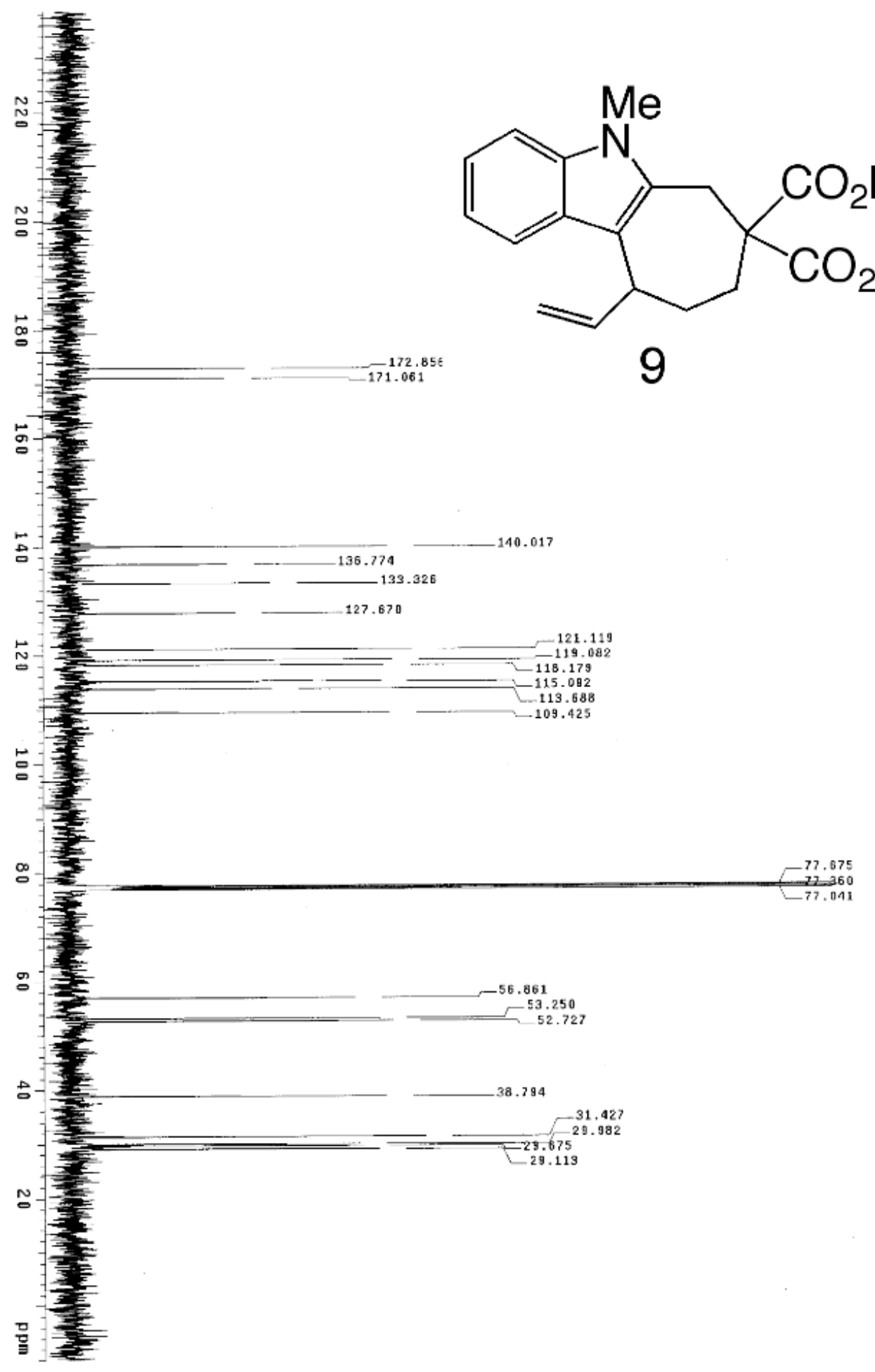


Figure S21. ${ }^{1} \mathrm{H}$ NMR spectrum of a 28:1 mixture of $(E)-12$ and $(Z)-12$.

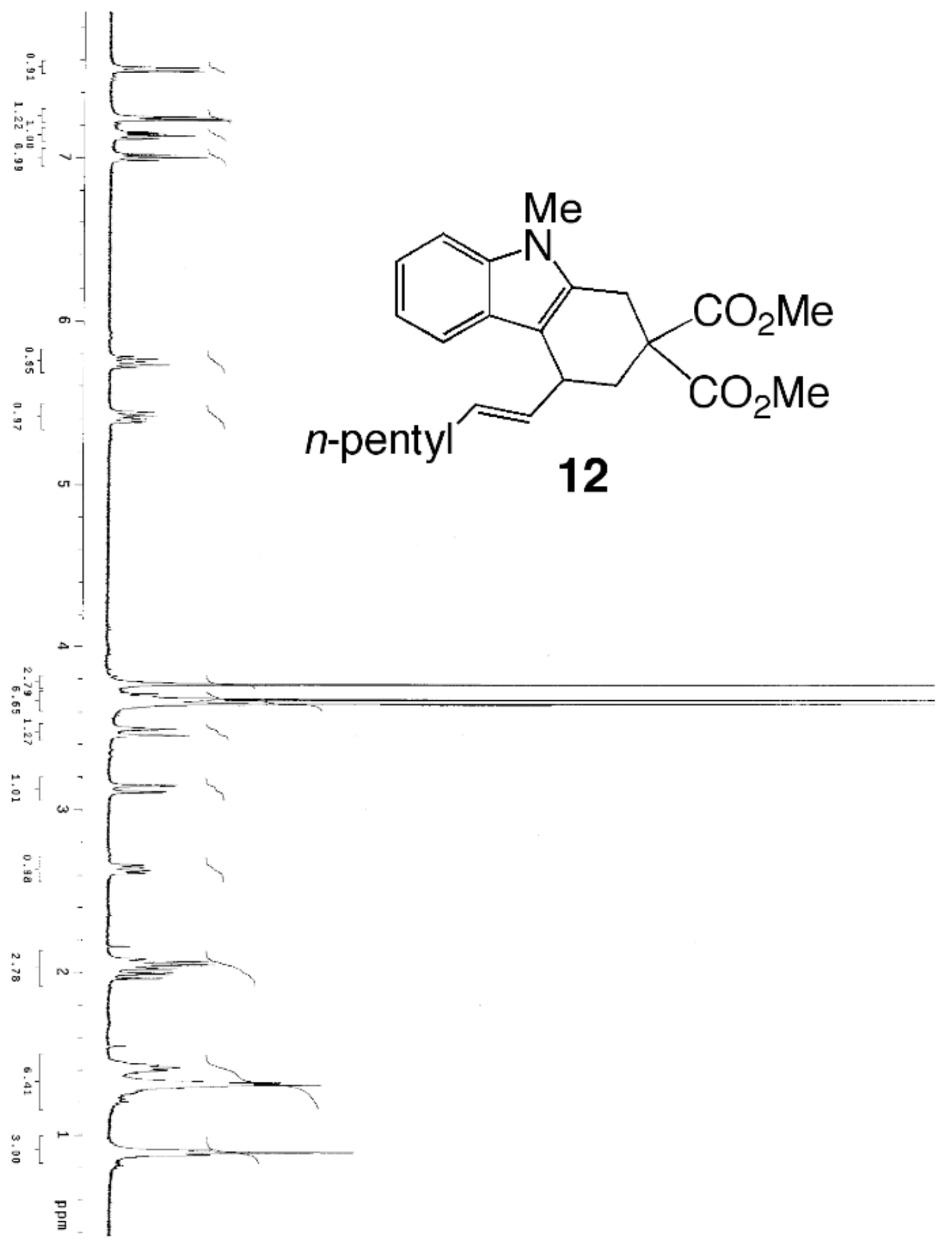


Figure S22. ${ }^{13} \mathrm{C}\left\{{ }^{1} \mathrm{H}\right\}$ NMR spectrum of a $28: 1$ mixture of $(E)-12$ and $(Z)-12$.

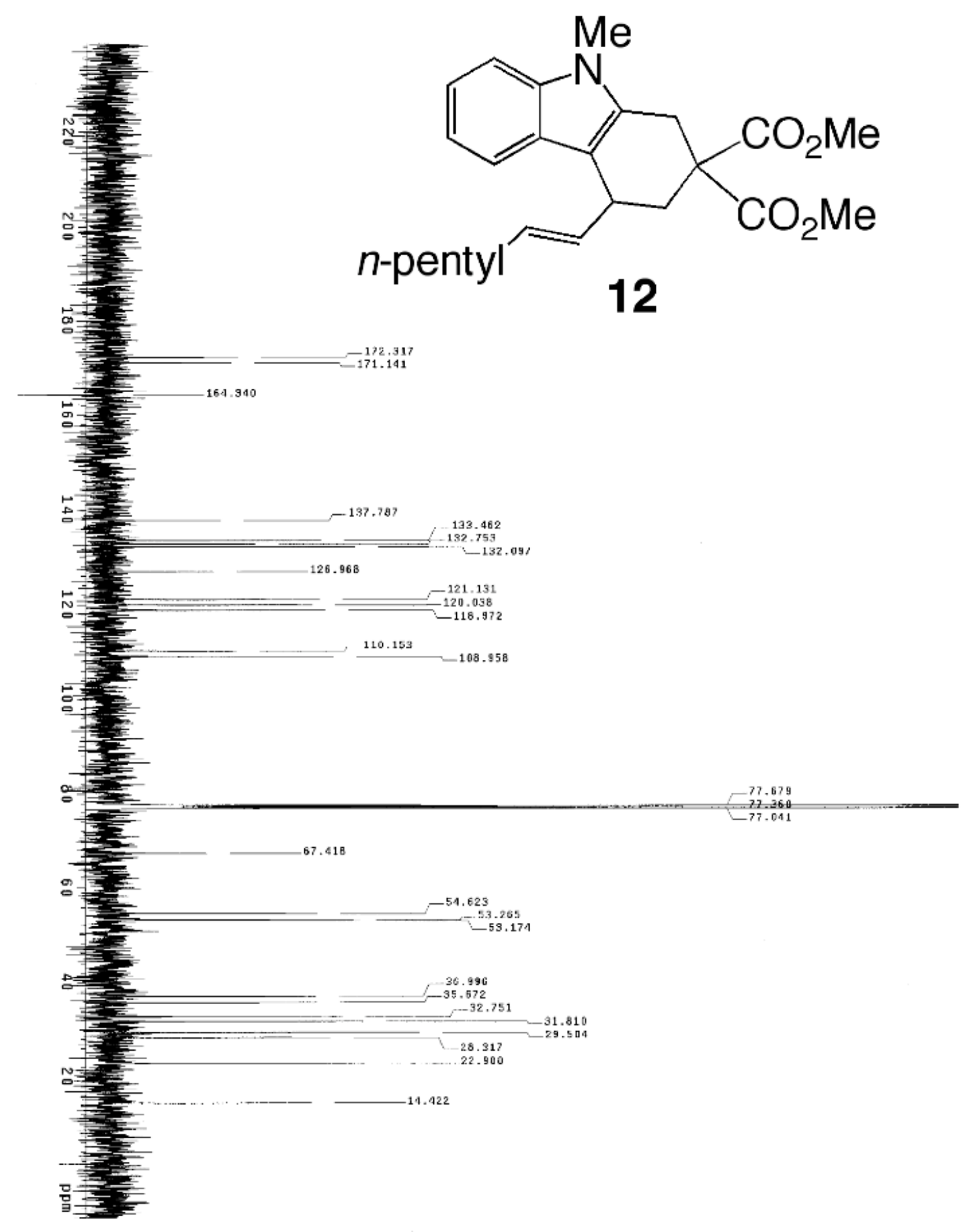


Figure S23. $\quad{ }^{1} \mathrm{H}$ NMR spectrum of a 9:1 mixture of $(E)-13$ and $(Z)-13$.

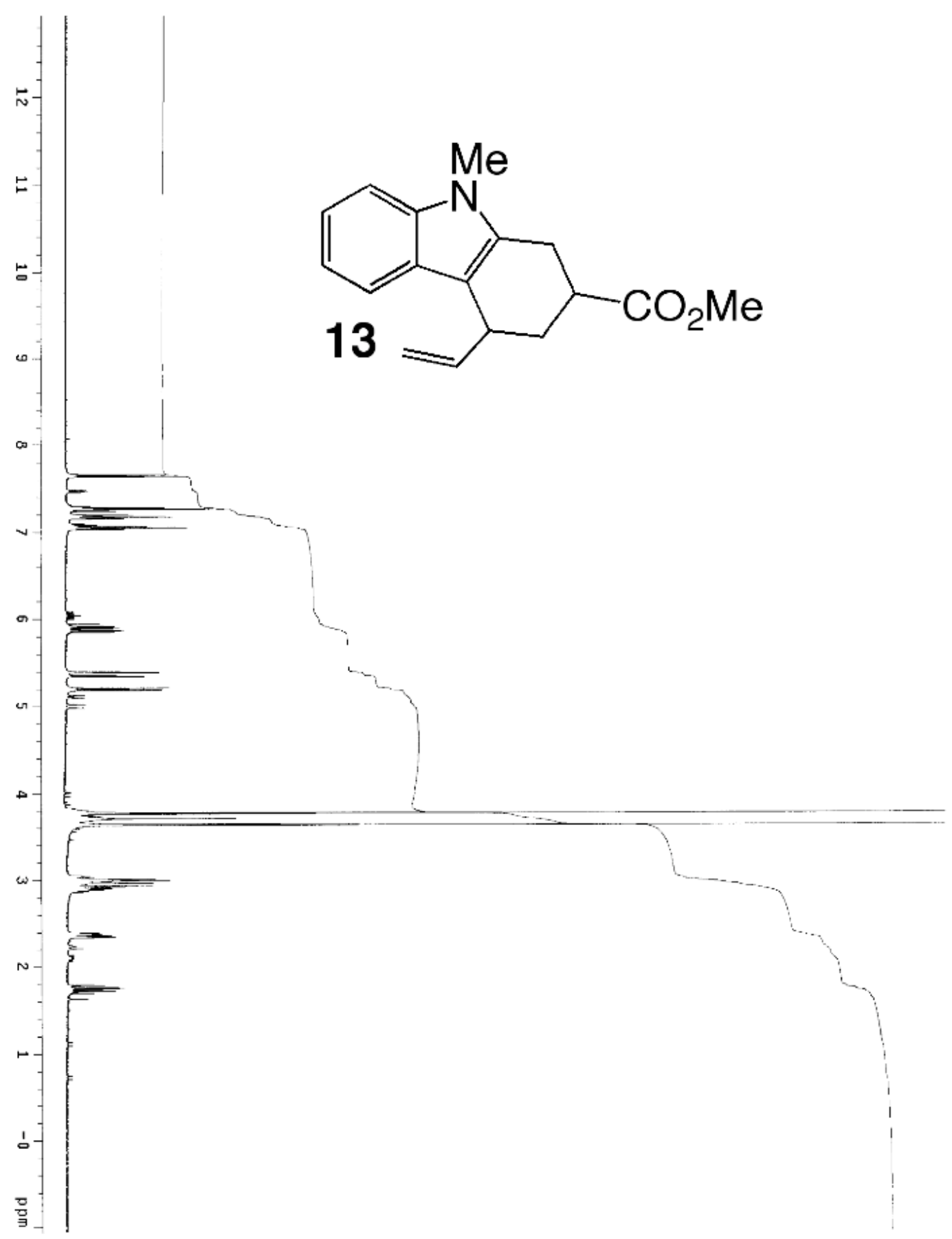


Figure S24. ${ }^{13} \mathrm{C}\left\{{ }^{1} \mathrm{H}\right\}$ NMR spectrum of a 9:1 mixture of $(E)-13$ and $(Z)-13$.

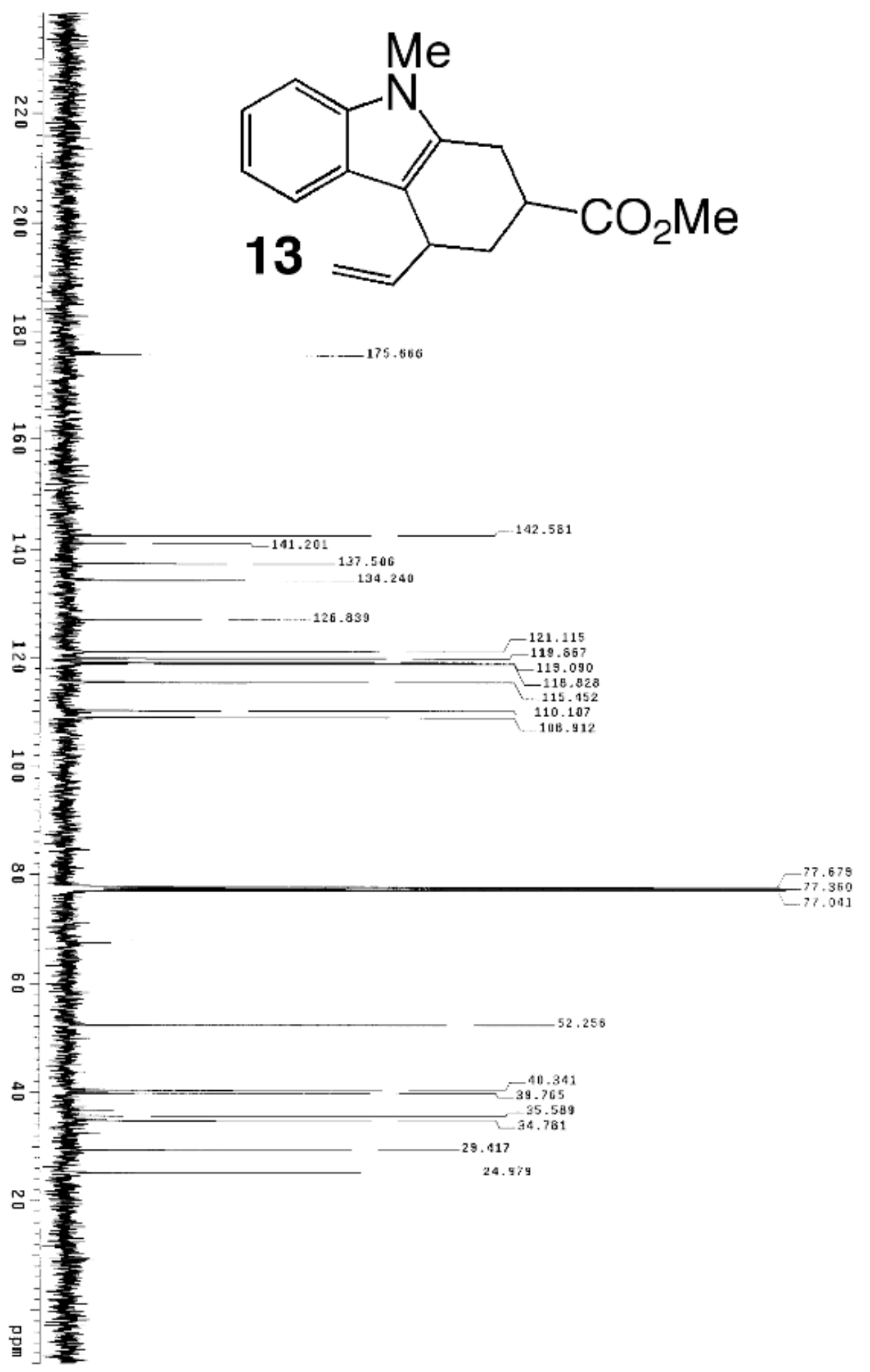




\section{References}

1) Zhang, Z.; Liu, C.; Kinder, R. E.; Han, H.; Qian, H.; Widenhoefer, R. A. J. Am. Chem. Soc. 2006, 128, 9066.

2) Munoz, M. P.; Adrio, J.; $\quad$ Carretero, J. C.; Echavarren, A. M. Organometallics 2005, 24, 1293. 